\title{
Effect of Barley yellow dwarf virus Infection on Yield and Malting Quality of Barley
}

Michael C. Edwards, USDA-ARS Northern Crop Science Laboratory, Fargo, ND 58105-5677; Thomas G. Fetch, Jr., Department of Plant Pathology, North Dakota State University, Fargo 58105; Paul B. Schwarz, Department of Cereal Science, North Dakota State University; and Brian J. Steffenson, Department of Plant Pathology, North Dakota State University

\begin{abstract}
Edwards, M. C., Fetch, T. G., Jr., Schwarz, P. B., and Steffenson, B. J. 2001. Effect of Barley yellow dwarf virus infection on yield and malting quality of barley. Plant Dis. 85:202-207.

Barley yellow dwarf virus (BYDV) infection occurs frequently in barley in the Upper Midwest region of the United States; however, the impact of this disease on the yield and quality of malting cultivars has not been adequately addressed. Studies were conducted at Fargo, North Dakota (from 1989 to 1990) to determine the effect of BYDV infection on yield and malt quality parameters in barley. Three malting cultivars varying in yield potential and malting characteristics were artificially inoculated at the seedling stage with a North Dakota BYDV isolate of the PAV serotype. Overall yields were reduced 32.5 to $38 \%$ in 1989 and 8.5 to $19.8 \%$ in 1990 by BYDV infection. Thousand-kernel weight (3.2 to 14.9\%) and kernel plumpness (11.9 to $38.9 \%$ ) also were reduced. Kernel color and three malt quality parameters ( $\alpha$-amylase, malt recovery, and wort viscosity) were not affected by BYDV infection. Increases in wort protein (2.5 to $14.5 \%$ ) and diastatic power (3.8 to $12.6 \%$ ), and decreases in malt extract (1.1 to 5.6\%) were found. Most notably, total protein increased 4.6 to $17.5 \%$ with BYDV infection. Higher proportions of thin seed, as a result of BYDV infection, contributed to the effects on several quality parameters. In summary, the negative effect of BYDV infection on overall quality is significant and should be considered when assessing the impact of this disease. Although annual BYD disease-related losses are typically not extensive in the Midwestern malting barley region, the incorporation of host resistance into recommended cultivars would ameliorate the negative effects of BYD disease on crop quality as well as on yield.
\end{abstract}

Additional keywords: crop loss, Hordeum vulgare

Barley yellow dwarf (BYD), the most common and widespread virus disease of cereal crops worldwide (14), may be caused by any one of several Barley yellow dwarf viruses (BYDVs) of the family Luteoviridae. Transmitted by at least 25 aphid species (24), these viruses historically have been classified into two subgroups and five strains based on aphid vector specificity and efficiency (31). However, each is now considered a member of the genus Luteovirus or Polerovirus, or is not yet assigned to a genus (37). BYDV-PAV, classified in the genus

Corresponding author: M. C. Edwards

E-mail: edwardsm@fargo.ars.usda.gov

Mention of a trademark name or a proprietary product does not constitute a guarantee or warranty of the product by the United States Department of Agriculture, nor does it imply approval to the exclusion of other products that also may be suitable.

Accepted for publication 30 October 2000.

Publication no. D-2000-1205-01R

This article is in the public domain and not copyrightable. It may be freely reprinted with customary crediting of the source. The American Phytopathological Society, 2001.
Luteovirus, is the predominant strain in North America, with the bird cherry-oat aphid (Rhopalosiphum padi L.) being its most efficient vector (25).

BYDVs have a large host range, infecting many grass species in the family Poaceae and all major cereal crops (15). Yield losses in the United States have been estimated at 1 to $3 \%$ annually (11) but, under environmental conditions favorable for the pathogen, losses up to $40 \%$ are not uncommon (10). In the Upper Midwest region of the United States, where most of this country's malting barley production is concentrated, BYDV infection occurs frequently, but is rarely severe. However, in 1999, a widespread and severe BYD disease epidemic occurred on barley (Hordeum vulgare L.), wheat (Triticum aestivum L.), and oat (Avena sativa $\mathrm{L}$.) in North Dakota, South Dakota, and Minnesota (B. Steffenson and M. McMullen, unpublished data). Late planting, combined with the early arrival of viruliferous aphids, contributed to this epidemic.

Many studies have been conducted to determine the effect of BYD disease on yield in cereal crops $(4,5,8,19,23,26,39)$. Oat is considered the cereal most susceptible to crop loss due to BYD disease, while barley is the second most damaged crop
(33). In fact, infection of barley at the seedling stage can result in up to $93 \%$ yield loss after artificial inoculation with BYDVs in field plots (6). Although many studies have been published on yield loss due to BYDV infection of oat and wheat, relatively little information is available on the effect of BYD disease on spring barley, especially malting cultivars.

In addition to direct losses in yield, barley producers may incur losses due to a reduction in quality. The number of quality requirements is greater for malting barley than for any other crop (9), and substantial price discounts can occur if the harvested grain is downgraded from premium malting-type to feed-type barley as a result of an inability to meet stringent malting quality standards. However, the effect of BYDV infection on malting quality components has not been adequately studied. The objective of this research was to determine the effect of BYDV infection on the yield and malting quality of three barley cultivars grown in the Upper Midwest region of the United States.

\section{MATERIALS AND METHODS}

Cultivars and planting protocols. The malting barley cvs. Morex (CI 15773), Robust (PI 476976), and Azure (CI 15865) were selected for this study. Morex is one of the industry standards for malting quality, and Robust is the most commonly grown cultivar in the Upper Midwest (1984 to 1999). Both Morex and Robust were developed by the Minnesota Agricultural Experiment Station. Azure is a malting cultivar with a blue aleurone bred at the North Dakota Agricultural Experiment Station. All three cultivars are susceptible to BYDV.

The cultivars were sown in the field with a six-row planter (45 $\mathrm{g}$ of seed per plot) on 4 May 1989 and 4 May 1990 at the North Dakota Agricultural Experiment Station (NDAES) in Fargo. Plots were $2 \mathrm{~m}$ wide by $3 \mathrm{~m}$ long with 2-by-2-m bare soil buffers separating each plot. The experimental design was a 2-by-3 factorial (infected versus noninfected treatments with three cultivars) in a randomized complete block with four replicates. Plots were maintained using agronomic practices standard for the region. In addition, hand weeding was done to remove weeds that could serve as virus reservoirs. 
Virus isolate and inoculation protocol. A North Dakota BYDV isolate, previously determined to be of the PAV serotype, was used in this study. Apterous aphids $(R$. padi) were increased for several weeks in a greenhouse on BYDV-infected, cv. Black Hulless barley (CI 666) prior to infestation of plants in the field using previously described protocols (13). Field plots were inoculated by placing Black Hulless barley leaves infested with viruliferous aphids (approximately eight Black Hulless plants/ meter/row) at the base of barley plants at the three-leaf growth stage (GS 13) (40). A $2.5-\mathrm{m}$ section of the center two rows of these plots was infested. Infested and noninfested plots were assigned at random. After a few hours, most aphids moved from the wilting source leaves onto the target barley plants and were allowed to feed for $72 \mathrm{~h}$. A contact insecticide (Malathion) then was applied (2.6 ml/liter) to all plots to kill the aphids. Observation of all plots prior to the first insecticide application revealed that aphids were present only in the infested rows of plots. A second application of Malathion was made 2 days later to kill any aphids surviving the first insecticide application. An application of a systemic insecticide (Orthene) was made $(7.8 \mathrm{ml} /$ liter $)$ to all plots at the flag leaf (GS 37) stage of development to reduce possible BYDV transmission by migrating aphids.

Disease assessment and agronomic traits. Plots were assessed for BYD disease at the flowering (GS 69) and middough (GS 85) stages of plant development. Percent disease incidence (percentage of plants exhibiting typical BYD disease symptoms) and severity (percentage of symptomatic leaf tissue of infected plants) were determined on plants in the center two rows of all plots. Random leaves were harvested from all plots and tested for the presence of BYDV using standard enzyme-linked immunosorbent assay (ELISA) procedures to verify that the chlorotic symptoms observed were indeed due to BYDV infection (12,30). To determine agronomic and malting quality parameters, the center two rows of each plot were hand-harvested, dried at $30^{\circ} \mathrm{C}$ for 2 days, hand-threshed, and cleaned. Yield was based upon the total dry kernel weight (in grams) produced per plot. The weight of 1,000 randomly selected kernels (thousand-kernel weight; TKW) for each plot also was recorded. The percentage of plump kernels (KP) was determined on a random 100-g subsample from each plot using a Niagara sample grader (Niagara Inc., Niagara, NY) according to American Society of Brewing Chemists (ASBC) method Barley-2C (2). Kernels retained on the top of a perforated sieve with 2.38 - by $19.05-\mathrm{mm}$ slotted openings were considered plump, and those passing through a perforated sieve with 1.98 - by $19.05-\mathrm{mm}$ slotted openings were considered thin.

Barley and malt quality parameters. Barley kernel color was determined according to a modification of ASBC method Barley-9 (2) using the L-value obtained from a Pacific Scientific XL-800 Gardner colorimeter with an XL-845 circumferential sensor (Pacific Scientific, Bethesda, $\mathrm{MD})$. The L-value was converted to a color score (1 to 10), with a value of 1 representing bright barley and a value of 10 representing dark or heavily stained barley. Total protein (TP) was determined using Kjeldahl method 46-10 of the American Association of Cereal Chemists (1) and the catalyst described by Williams (38).

Micromalting of barley was conducted prior to malt quality analysis using equipment and procedures previously described (28). Seed was germinated for 4 days at $16^{\circ} \mathrm{C}$ and approximately $95 \%$ relative humidity. Malt quality analyses were performed using standard or modified methods of the ASBC (2) as described by Karababa et al. (28). Malt quality parameters assayed were malt recovery (MR), malt extract (ME), wort viscosity (WV), wort protein (WP), diastatic power (DP), and $\alpha$-amylase (AA).

Data analyses. Data were analyzed with Statistical Analysis System software (SAS
Institute, Cary, NC). PROC TTEST procedures were used to compare the effect of infected versus noninfected treatments (by cultivar) for each dependent variable (yield, TKW, KP, color, TP, MR, ME, WV, WP, DP, and AA). Statistics ( $t$ test and $P r$ $>t$ ) were calculated to determine if variances were equal, with a level of significance established at $P>0.05$.

\section{RESULTS AND DISCUSSION}

Plants that were infested with viruliferous aphids developed the classic yellowing symptoms of BYD disease, with chlorosis beginning at the leaf tips and extending down the leaf blades. In all cases, random leaf samples from infected plants tested positive for BYDV, while random leaf samples from noninfected plants in adjacent plots were negative for BYDV. In 1989, infection was severe in infested plots of the three cultivars as the mean BYD disease incidence and severity at the soft dough stage ranged from 98.5 to $99.0 \%$ and 67.5 to $76.3 \%$, respectively (Table 1). In contrast, infection levels in noninfested plots were very low, ranging from 0.8 to $1.0 \%$ in incidence and 0.5 to $1.0 \%$ in severity. Infection was less severe in 1990, as mean BYD disease incidence in infected plots ranged from 67.5 to $96.5 \%$ at the soft dough stage. Mean BYD disease severity also was lower, ranging from 6.3 to $23.8 \%$ at flowering and from 26.3 to $32.5 \%$ at the soft dough stage. However, although BYD disease incidence was very low in noninfested plots (0 to $1.3 \%$ at GS 69 and 1.5 to $2.0 \%$ at GS 85), BYD disease severity in these plots was slightly higher (0 to $7.5 \%$ at GS 69 and 7.3 to $9.5 \%$ at GS $85)$ compared to 1989 . Morex and Robust showed high levels of infection in both years, whereas the incidence of BYD disease in Azure plots was lower in 1990. Although the extent to which environmental factors influenced these studies cannot be precisely determined, the generally greater BYD disease severity in 1989 could have been related

Table 1. Mean incidence and severity of Barley yellow dwarf virus (BYDV) infection in plots of barley cvs. Azure, Morex, and Robust infested and not infested with viruliferous aphids (Rhopalosiphum padi) in 1989 and 1990 at Fargo, ND

\begin{tabular}{|c|c|c|c|c|c|c|c|c|c|c|c|c|}
\hline \multirow[b]{3}{*}{ Year, cvs. } & \multicolumn{6}{|c|}{ Mean incidence $^{\mathbf{a}}$} & \multicolumn{6}{|c|}{ Mean severity $^{\mathbf{b}}$} \\
\hline & \multicolumn{3}{|c|}{ Flowering stage (GS 69) ${ }^{\mathrm{c}}$} & \multicolumn{3}{|c|}{ Soft dough stage (GS 85) } & \multicolumn{3}{|c|}{ Flowering stage (GS 69) } & \multicolumn{3}{|c|}{ Soft dough stage (GS 85) } \\
\hline & Noninfested & Infested & $\operatorname{Pr}>t^{\mathrm{d}}$ & Noninfested & Infested & $\operatorname{Pr}>t$ & Noninfested & Infested & $P r>t$ & Noninfested & Infested & $\operatorname{Pr}>t$ \\
\hline \multicolumn{13}{|l|}{1989} \\
\hline Azure & $\ldots$ & $\ldots$ & $\ldots$ & 0.8 & 98.5 & $<0.0001$ & $\ldots$ & $\ldots$ & $\ldots$ & 0.5 & 67.5 & $<0.0001$ \\
\hline Morex & $\ldots$ & $\ldots$ & $\ldots$ & 1.0 & 99.0 & $<0.0001$ & $\ldots$ & $\ldots$ & $\ldots$ & 0.8 & 75.0 & $<0.0001$ \\
\hline Robust & $\ldots$ & $\ldots$ & $\ldots$ & 1.0 & 99.0 & $<0.0001$ & $\ldots$ & $\ldots$ & $\ldots$ & 1.0 & 76.3 & $<0.0001$ \\
\hline \multicolumn{13}{|l|}{1990} \\
\hline Azure & 1.3 & 32.5 & 0.0027 & 1.5 & 67.5 & 0.0001 & 2.5 & 6.3 & 0.0972 & 7.3 & 32.5 & 0.0005 \\
\hline Morex & 0.0 & 65.0 & 0.0001 & 1.5 & 96.5 & $<0.0001$ & 0.0 & 6.3 & 0.0025 & 9.5 & 26.3 & 0.0201 \\
\hline Robust & 0.5 & 73.8 & 0.0001 & 2.0 & 91.3 & $<0.0001$ & 7.5 & 23.8 & 0.0167 & 7.8 & 32.5 & 0.0081 \\
\hline
\end{tabular}

a Mean incidence is the percentage of plants within a plot with BYDV symptoms averaged over four replicates.

${ }^{\mathrm{b}}$ Mean severity is the percentage of symptomatic leaf tissue/plant with BYDV symptoms averaged over four replicates.

${ }^{\mathrm{c}}$ Flowering and soft dough stages of development based on growth stages according to Zadoks et al. (40); .. = disease assessment at the flowering stage not recorded in 1989.

${ }^{\mathrm{d}}$ Probability of noninfested and infested treatment means being equal, as calculated by the paired $t$ test. 
to the warmer and drier growing conditions in that year $(34,36)$.

Yield and TKW were significantly reduced by BYDV infection (Table 2). Plot yields were reduced 32.5 to $38.0 \%$ and 8.5 to $19.8 \%$ by BYDV infection in 1989 and 1990, respectively. It should be noted that yields of even healthy checks were lower in 1989 than in 1990 as a result of the warmer and drier growing conditions that year. Average yields of commercially grown barley were lower in 1989 than in 1990 as well $(34,36)$. Reductions in TKW ranged from 7.2 to $14.9 \%$ in 1989 ; whereas, in 1990, only Azure (9.9\%) exhibited a statistically significant reduction in TKW at the $P=0.05$ level. These yield and TKW reductions are somewhat lower than those reported in some previous studies, even though high levels of infection were recorded in our inoculated plots. For example, Pike (33) observed yield reductions of 14.8 to $93.2 \%$ (mean of $54.5 \%$ ) in barley inoculated at the seedling stage (33). In Montana (in 1985), average yield reductions of $65.1 \%$ in six-rowed barley and TKW reductions exceeding $28 \%$ were recorded (39). Gill et al. (21) found yield losses of $67 \%$ in the six-rowed barley cv. Conquest when artificially inoculated at the two-leaf stage in the field, whereas natural infections of BYDV in Manitoba (mean incidence of 52.5\%) in 1969 caused an estimated yield loss of $65 \%$ in cv. Herta, a highly susceptible two-rowed barley (20). The wide range in yield and TKW reductions found among studies could be due to differences in susceptibility or tolerance of the cultivars tested, virulence of the virus isolates used, environmental influences, or combinations of these factors.

Plumpness of grain from all plots grown in 1990, including checks, was considerably greater than from those grown in 1989, presumably due to moderate temperatures and timely rains during the kernel filling period in 1990. Nevertheless, seed size was significantly reduced by BYDV infection in both years (Table 2). Azure and Morex were considerably more affected by BYDV infection, with approximately 10 to $13 \%$ more loss in plumpness compared to Robust. In comparison, a 41 to $48 \%$ reduction in seed size was found with BYDV-infected six-rowed winter barleys in Missouri (23). These marked reductions in seed size can affect the quality and market price of the grain. If harvested grain does not meet minimum plumpness standards for malting grade (3), it is discounted as feed barley. The malting industry prefers plump kernels because they contain greater amounts of starch, which, in turn, results in higher yields of malt extract. Acceptable levels of kernel plumpness vary with the crop year. The 10year average (1989 to 1999) for Midwestern six-rowed malting barley is $71 \%$ (7). Although kernel plumpness of $78 \%$ or higher is considered ideal for Midwestern six-rowed malting barley (35), barley with at least $70 \%$ plump seeds is often accepted for malting.

Significantly higher total protein was found in grain harvested from infected plots of all cultivars in 1989 (Table 3). In 1990, Morex was the only cultivar that exhibited a significant increase in protein as a result of infection, although the others showed smaller increases. The effect of infection on total protein was most pronounced in 1989, when an average increase of $14.3 \%$ was observed. The higher grain protein levels found here are consistent with the results of previous studies regarding the physiological effects of BYDV infection $(18,27,32)$. Photosynthesis and translocation are reduced in infected barley, with a concomitant increase in the accumulation of sugars and starch in the leaves $(27,32)$. This reduction in translocation probably explains the higher relative protein levels in the grain as found here. Relative protein levels in wheat grain from BYDV-infected plants also increase as a result of reduced translocation and reduced starch accumulation in grain (18). The impact of BYDV infection on grain protein level is at least partially related to a decrease in kernel size. A significantly higher percentage of thin kernels was found for all cultivars infected with BYDV in 1989 and for Azure in 1990 (Table 3). Pronounced differences in barley kernel composition can result from differences in kernel filling (17). With a reduction in fill, kernels are thinner and the ratio of endosperm to husk

Table 2. Effect of Barley yellow dwarf virus infection on yield, thousand kernel weight, and percentage of plump kernels of barley cvs. Azure, Morex, and Robust grown in the field in 1989 and 1990 at Fargo, ND

\begin{tabular}{|c|c|c|c|c|c|c|c|c|c|c|c|c|}
\hline \multirow[b]{2}{*}{ Year, cvs. } & \multicolumn{4}{|c|}{ Yield (g/plot) ${ }^{\mathrm{a}}$} & \multicolumn{4}{|c|}{ Thousand kernel weight (g) } & \multicolumn{4}{|c|}{ Plump kernels $(\%)^{\mathbf{b}}$} \\
\hline & Non & Inf & $\operatorname{Pr}>t$ & Diff $(\%)$ & Non & Inf & $P r>t$ & Diff (\%) & Non & Inf & $P r>t$ & Diff $(\%)$ \\
\hline \multicolumn{13}{|l|}{1989} \\
\hline Azure & 356.25 & 220.75 & 0.0074 & -38.0 & 31.51 & 26.83 & 0.0005 & -14.9 & 52.16 & 31.87 & 0.0022 & -38.9 \\
\hline Morex & 350.75 & 217.50 & 0.0002 & -38.0 & 31.03 & 28.81 & 0.0067 & -7.2 & 44.28 & 28.60 & 0.0149 & -35.4 \\
\hline Robust & 296.50 & 200.25 & 0.0067 & -32.5 & 32.16 & 28.43 & 0.0011 & -11.6 & 50.87 & 37.79 & 0.0413 & -25.7 \\
\hline \multicolumn{13}{|l|}{1990} \\
\hline Azure & 724.75 & 663.00 & 0.0493 & -8.5 & 38.45 & 34.63 & 0.0010 & -9.9 & 89.52 & 67.57 & 0.0009 & -24.5 \\
\hline Morex & 618.50 & 500.50 & 0.0379 & -19.1 & 32.27 & 31.25 & 0.5558 & -3.2 & 64.64 & 47.16 & 0.0158 & -27.0 \\
\hline Robust & 624.75 & 501.00 & 0.0032 & -19.8 & 35.94 & 34.31 & 0.0692 & -4.5 & 80.69 & 71.11 & 0.1464 & -11.9 \\
\hline
\end{tabular}

a Non = noninfected; Inf $=$ infected; $P r>t=$ probability of non-infected and infected treatment means being equal, as calculated by the paired $t$ test; and

Diff $(\%)=$ percent difference is the increase $(+)$ or decrease $(-)$ of the infected treatment plot value compared to that of the noninfected plot.

${ }^{\mathrm{b}}$ Plump kernels = percent (by weight) of barley kernels in a 100-g sample retained on a sieve with 2.38-by-19.05-mm slotted openings.

Table 3. Effect of Barley yellow dwarf virus infection on total protein, thin kernels, and malt extract in barley cvs. Azure, Morex, and Robust grown in the field in 1989 and 1990 at Fargo, ND

\begin{tabular}{|c|c|c|c|c|c|c|c|c|c|c|c|c|}
\hline \multirow[b]{2}{*}{ Year, cvs. } & \multicolumn{4}{|c|}{ Total protein (\% dry basis) ${ }^{a}$} & \multicolumn{4}{|c|}{ Thin kernels $(\%)^{b}$} & \multicolumn{4}{|c|}{ Malt extract (\%) } \\
\hline & Non & Inf & $\operatorname{Pr}>t$ & Diff $(\%)$ & Non & Inf & $\operatorname{Pr}>t$ & Diff $(\%)$ & Non & Inf & $\operatorname{Pr}>t$ & $\operatorname{Diff}(\%)$ \\
\hline \multicolumn{13}{|l|}{1989} \\
\hline Azure & 14.54 & 17.08 & 0.0011 & +17.5 & 2.92 & 14.63 & 0.0002 & +401.0 & 77.63 & 73.63 & 0.0001 & -5.2 \\
\hline Morex & 15.46 & 17.37 & 0.0316 & +12.4 & 4.25 & 7.37 & 0.0278 & +73.4 & 76.90 & 73.93 & 0.0019 & -3.9 \\
\hline Robust & 15.88 & 17.95 & 0.0016 & +13.0 & 3.79 & 11.31 & 0.0008 & +198.4 & 77.78 & 73.40 & 0.0002 & -5.6 \\
\hline \multicolumn{13}{|l|}{1990} \\
\hline Azure & 14.05 & 14.71 & 0.1754 & +4.7 & 1.25 & 3.14 & 0.0397 & +151.2 & 79.58 & 77.55 & 0.0955 & -2.6 \\
\hline Morex & 13.72 & 15.02 & 0.0009 & +9.5 & 4.20 & 4.73 & 0.6585 & +12.6 & 79.00 & 76.60 & 0.0044 & -3.0 \\
\hline Robust & 13.96 & 14.60 & 0.2576 & +4.6 & 1.99 & 4.18 & 0.1359 & +110.1 & 78.90 & 78.03 & 0.2856 & -1.1 \\
\hline
\end{tabular}

${ }^{\mathrm{a}}$ Non $=$ noninfected; Inf $=$ infected; $P r>t=$ probability of non-infected and infected treatment means being equal, as calculated by the paired $t$ test; and Diff $(\%)=$ percent difference is the increase $(+)$ or decrease $(-)$ of the infected treatment plot value compared to that of the noninfected plot.

${ }^{\mathrm{b}}$ Thin kernels $=$ percentage of barley kernels in a 100-g sample that passes through a 1.98-by-19.05-mm slotted sieve. 
tends to decrease. Furthermore, starch is the principal component of grain (16); thin kernels have less starch and a relatively higher proportion of protein.

Unlike durum and bread wheats, where growers receive premium prices for higher protein levels, malting barley with protein in excess of $13.5 \%$ is rarely used for malt (9). Percent total protein is considered crucial because of its value as a predictor of other quality parameters. High protein levels in malting barley can be associated with processing problems, such as longer steeping times, increased malting losses, erratic germination, increased wort and beer color, and haze formation in beer (9). Most importantly, higher protein levels are undesirable because malt extract levels decrease as protein levels increase.

Malt extract is a measure of the soluble material obtained following laboratory extraction (mashing; 9). Extracts are prepared by mixing finely ground malt with water, and subjecting the mixture to a time-temperature program that favors protein and starch hydrolysis. The specific gravity of the filtered mash (referred to as the wort) is determined for the calculation of extract. The level of malt extract is of preeminent concern to the brewer, because it helps to determine the amount of beer that can be produced from a given amount of malt. Since total protein generally increased as a result of BYDV infection, reductions in malt extract due to $\mathrm{BYDV}$ infection were expected. Such reductions in extract were observed in all instances, but were not always significant (Table 3 ). The greatest reductions were evident in 1989. Although reductions in malt extract observed with BYDV-infected samples correlated with an increase in total protein levels, reductions were also related to decreased kernel size. This is understandable, given that malt extract is primarily composed of starch-derived sugars and dextrins. As thinner kernels have less starch and a greater proportion of husk and protein, extract is reduced.

Kernel color is an important consideration in the purchase of malting barley, because stained or discolored kernels are often indicative of microbial infection (22). Barley that is not bright in color is discounted at the elevator and may not be purchased for malting. Our results indicate that kernel color generally was not affected by BYDV infection (Table 4). In 1989, infected plots of Azure and Robust produced significantly brighter grain than check plots. However, the magnitude of this increase was small, and was not perceptible by visual means. It also should be noted that samples of Azure and Robust in 1989 were quite thin. Seed size will affect sample packing in the cell of the colorimeter, which, in turn, may affect color measurement. Thus, the slight increase in color score for 1989 samples may have been an artifact of reduced seed size, especially in light of the fact that there were no significant differences in seed color between infected and check plots in 1990.

Although BYDV infection increased total protein and decreased malt extract, other malting quality parameters were not greatly affected. More significant differences between infected and noninfected treatments were observed in 1989 than in 1990 for several of these other malting quality variables, presumably due to greater disease severity in 1989 (Tables 4 and 5). The most striking example of this was the effect of BYD disease on DP, although differences between infected and noninfected plots were actually greater in 1990 in the case of AA.

The principle measures of amylolytic activity in malt are AA and DP (29). Together, they provide an indication of the ability of the malt to convert starch to fermentable sugars and nonfermentable dextrins. AA is a direct measure of all AA isozymes. Although the DP assay is a measure of all enzymes that are involved in the production of reducing sugars, it is principally a measure of $\beta$-amylase. The AAs are synthesized de novo during germination, whereas the $\beta$-amylases are present in the endosperm of mature grain. Significant differences in AA levels were not detected between samples from infected and control plots for either year (Table 4). However, the DP levels of grain from in-

Table 4. Effect of Barley yellow dwarf virus infection on kernel color, diastatic power, and $\alpha$-amylase in barley cvs. Azure, Morex, and Robust grown in the field in 1989 and 1990 at Fargo, ND

\begin{tabular}{|c|c|c|c|c|c|c|c|c|c|c|c|}
\hline \multirow[b]{2}{*}{ Year, cvs. } & \multicolumn{3}{|c|}{ Kernel color ${ }^{\mathrm{a}}$} & \multicolumn{4}{|c|}{ Diastatic power $\left({ }^{\circ}\right)$} & \multicolumn{4}{|c|}{$\alpha$-Amylase (DU) ${ }^{b}$} \\
\hline & Non & Inf & $\operatorname{Pr}>t$ & Non & Inf & $P r>t$ & Diff $(\%)$ & Non & Inf & $\operatorname{Pr}>t$ & Diff $(\%)$ \\
\hline \multicolumn{12}{|l|}{1989} \\
\hline Azure & 2.25 & 1.00 & 0.0025 & 164.40 & 179.75 & 0.0042 & +9.3 & 59.25 & 56.90 & 0.4875 & -4.0 \\
\hline Morex & 1.00 & 1.00 & 0.9999 & 177.15 & 199.53 & 0.0004 & +12.6 & 68.40 & 69.73 & 0.6050 & +1.9 \\
\hline Robust & 2.00 & 1.25 & 0.0240 & 178.75 & 197.17 & 0.0010 & +10.3 & 46.90 & 46.75 & 0.9337 & -0.3 \\
\hline \multicolumn{12}{|l|}{1990} \\
\hline Azure & 5.00 & 4.75 & 0.7796 & 227.53 & 236.10 & 0.3460 & +3.8 & 67.58 & 72.68 & 0.2221 & +7.5 \\
\hline Morex & 2.00 & 2.25 & 0.6202 & 261.28 & 275.68 & 0.1911 & +5.5 & 89.25 & 95.00 & 0.0875 & +6.4 \\
\hline Robust & 3.00 & 3.75 & 0.5239 & 262.58 & 279.60 & 0.2096 & +6.5 & 53.53 & 59.78 & 0.0589 & +11.7 \\
\hline
\end{tabular}

${ }^{\mathrm{a}}$ Non $=$ noninfected; $\mathrm{Inf}=$ infected; $P r>t=$ probability of non-infected and infected treatment means being equal, as calculated by the paired $t$ test; and

Diff $(\%)=$ percent difference is the increase $(+)$ or decrease $(-)$ of the infected treatment plot value compared to that of the noninfected plot.

b $20^{\circ}$ dextrinizing units.

Table 5. Effect of Barley yellow dwarf virus infection on wort protein, wort viscosity, and malt recovery in barley cvs. Azure, Morex, and Robust grown in the field in 1989 and 1990 at Fargo, ND

\begin{tabular}{|c|c|c|c|c|c|c|c|c|c|c|c|c|}
\hline \multirow[b]{2}{*}{ Year, cvs. } & \multicolumn{4}{|c|}{ Wort protein $(\%)^{\mathrm{a}}$} & \multicolumn{4}{|c|}{ Wort viscosity $(\mathbf{c P})^{\mathbf{b}}$} & \multicolumn{4}{|c|}{ Malt recovery $^{c}$} \\
\hline & Non & Inf & $\operatorname{Pr}>t$ & Diff $(\%)$ & Non & Inf & $\operatorname{Pr}>t$ & Diff (\%) & Non & Inf & $P r>t$ & Diff $(\%)$ \\
\hline \multicolumn{13}{|l|}{1989} \\
\hline Azure & 4.32 & 4.91 & 0.0197 & +13.7 & 1.47 & 1.46 & 0.6836 & -0.7 & 89.70 & 89.30 & 0.3470 & -4.4 \\
\hline Morex & 4.69 & 5.37 & 0.0004 & +14.5 & 1.43 & 1.41 & 0.1708 & -1.4 & 89.17 & 89.59 & 0.2277 & +4.7 \\
\hline Robust & 4.78 & 5.02 & 0.0624 & +5.0 & 1.43 & 1.42 & 0.5322 & -0.7 & 88.93 & 89.19 & 0.5496 & +2.9 \\
\hline \multicolumn{13}{|l|}{1990} \\
\hline Azure & 5.78 & 5.74 & 0.9008 & -0.7 & 1.54 & 1.60 & 0.0119 & +3.9 & 87.71 & 89.81 & 0.1130 & +2.4 \\
\hline Morex & 5.60 & 5.96 & 0.0124 & +6.4 & 1.52 & 1.54 & 0.5226 & +1.3 & 87.65 & 88.72 & 0.2107 & +1.2 \\
\hline Robust & 5.54 & 5.68 & 0.5380 & +2.5 & 1.54 & 1.53 & 0.5945 & -0.6 & 89.62 & 89.47 & 0.6846 & -1.6 \\
\hline
\end{tabular}

${ }^{a}$ Non = noninfected; Inf = infected; $P r>t=$ probability of non-infected and infected treatment means being equal, as calculated by the paired $t$ test; and Diff $(\%)=$ percent difference is the increase $(+)$ or decrease $(-)$ of the infected treatment plot value compared to that of the noninfected plot.

$\mathrm{b}$ Centipoises $=\mathrm{cP}$.

${ }^{c}$ Malt recovery was determined as the percent of sample weight (dry basis) retained following the malting process and removal of rootlets. 
fected plots were significantly higher than those of the controls in 1989 (Table 4). This increase was likely related to the significant reduction in kernel size that was observed in BYDV-infected plots in 1989. As previously stated, thin kernels contain less starch and a higher relative proportion of protein. $\beta$-Amylase is a component of the endosperm protein; therefore, a concomitant increase in DP in these thin samples was not surprising.

BYDV infection had a variable effect on WP and WV. Significant increases in WP due to BYDV infection were found for Azure and Morex in 1989 and for Morex in 1990 (Table 5). The increase in WP was primarily related to the higher total protein levels in samples from BYDV-infected plots. Adequate levels of WP are required for beer foam and proper yeast growth during fermentation. An average level of WP across all cultivars for commercially grown Midwestern six-rowed malting barley is $5.5 \%$ (35). Wort protein in excess of 5.5 to $6 \%$ is associated with reduced overall malt extract, increased wort and beer color, and the potential for haze problems in beer. Although the WP values determined here may not be directly comparable to those derived commercially, the magnitude of the increases in WP found as a result of BYDV infection might be sufficient to cause quality problems. Whereas BYDV infection generally increased WP, there was little effect on WV. Significant differences in WV were only found for Azure barley in 1990. Wort viscosity is largely related to the presence of soluble $\beta$ $(1,3),(1,4)$-glucans in the wort. The $\beta$ $(1,3),(1,4)$-glucans are the major components of the endosperm cell walls, and WVs of $1.5 \mathrm{cP}$ or lower are generally indicative of adequate cell wall breakdown during malting.

Finally, BYDV infection did not significantly affect malt recovery (Table 5). Malt recovery is the weight of malt recovered (percent) following malting and removal of rootlets. Sources of loss during malting can be generally categorized as solubles lost during steeping, respiration losses, and loss attributable to rootlet growth (29). BYDV infection did not appear to significantly affect any of these processes.

In summary, though reductions in several malt quality parameters may not have been significant, BYDV infection generally increased total protein and decreased malt extract to undesirable levels. Since failure to meet malting quality standards results in a significant price discount, factors reducing the quality as well as the yield of grain should be minimized. Unfortunately, some of the factors most influential on the level of BYDV infection in this region, planting date and the date of aphid arrival, are beyond the control of cereal producers. Incorporation of resistance into malting barley cultivars remains the most effective and economical option for ameliorating the effects of this disease on malting quality.

\section{ACKNOWLEDGMENTS}

This research was supported in part by the American Malting Barley Association of Milwaukee, WI.

\section{LITERATURE CITED}

1. American Association of Cereal Chemists. 1983. Approved Methods of the American Society of Brewing Chemists. Am. Assoc. Cereal Chem. St. Paul, MN.

2. American Society of Brewing Chemists. 1992. Methods of Analysis of the American Society of Brewing Chemists, 8th ed. Am. Soc. Brew. Chem. St. Paul, MN.

3. Anonymous. 1997. United States Standards for Grain. In: USDA-GIPSA Handbook 2: Barley. P. a. S. A. United States Grain Inspection, ed. U.S. Gov. Print. Off. Washington, DC.

4. Baltenberger, D. E., Ohm, H. W., and Foster, J. E. 1987. Reactions of oat, barley, and wheat to infection with barley yellow dwarf virus isolates. Crop Sci. 27:195-198.

5. Banks, P. M., Davidson, J. L., Bariana, H. S., and Larkin, P. J. 1995. Effects of barley yellow dwarf virus on the yields of winter wheat. Aust. J. Agric. Res. 46:935-946.

6. Banttari, E. E. 1965. Occurrence of aster yellows in barley in the field and its comparison with BYD. Phytopathology 55:838-843.

7. Barr, J. M., Schwarz, P. B., Harrold, R. L., Kapphahn, M. E., and Gordon, D. T. 1999. 1999 Regional Barley Crop Quality Report: North Dakota and Minnesota. N. D. Barley Council Fargo.

8. Bauske, E. M., Bissonnette, S. M., and Hewings, A. D. 1997. Yield loss assessment of barley yellow dwarf disease on spring oat in Illinois. Plant Dis. 81:485-488.

9. Burger, W. C., and LaBerge, D. E. 1985. Malting and brewing quality. Pages 367-401 in: Barley. D. C. Rasmusson, ed. Am. Soc. Agron. Madison, WI.

10. Burnett, P. A. 1984. Preface. Pages 6-13 in: Barley Yellow Dwarf, A Proceedings of the Workshop, CIMMYT, Mexico, D.F., Mexico.

11. Burnett, P. A., and Mezzalama, M. 1990. The barley yellow dwarf screening program at CIMMYT. Pages 434-440 in: World Perspectives on Barley Yellow Dwarf. P. A. Burnett, ed. CIMMYT Mexico, D.F., Mexico.

12. Clark, M. F., and Adams, A. M. 1977. Characteristics of the microplate method of enzyme-linked immunosorbent assay for the detection of plant viruses. J. Gen. Virol. 34:475-483.

13. Comeau, A. 1984. Aphid rearing and screening methods for resistance to barley yellow dwarf virus in cereals, Pages 60-71 in: Barley Yellow Dwarf, A Proceedings of the Workshop, CIMMYT, Mexico, D.F., Mexico.

14. Conti, M., D'Arcy, C. J., and Jedlinsky, H. 1990. The "yellow plague" of cereals, barley yellow dwarf virus, Pages 1-6 in: World Perspectives on Barley Yellow Dwarf. P. A. Burnett, ed. CIMMYT Mexico, D.F., Mexico.

15. D'Arcy, C. J. 1995. Symptomatology and host range of barley yellow dwarf. Pages 9-28 in: Barley Yellow Dwarf: 40 Years of Progress. C. J. D'Arcy and P. A. Burnett, eds. American Phytopathological Society Press, St. Paul, MN.

16. Duffus, C. M., and Cochrane, M. P. 1992. Grain structure and composition, Pages 291318 in: Barley: Genetics, Biochemistry, Molecular Biology, and Biotechnology. P. R. Shewry, ed. CAB International, Oxon, UK.

17. Duijnhouwer, I. D. C., Grasshoff, C., and Angelino, S. A. G. F. 1993. Kernel filling and malting barley quality. Proc. Eur. Brew. Conv.
24:121-128.

18. Fitzgerald, P. J., and Stoner, W. N. 1967. Barley yellow dwarf studies in wheat (Triticum aestivum L.). Yield and quality of hard red winter wheat infected with barley yellow dwarf virus. Crop Sci. 7:337-341.

19. Gildow, F. E., and Frank, J. A. 1988. Barley yellow dwarf virus in Pennsylvania: effect of the PAV isolate on yield components of Noble spring oats. Plant Dis. 72:254-256.

20. Gill, C. C. 1970. Epidemiology of barley yellow dwarf in Manitoba and effect of the virus on yield of cereals. Phytopathology 60:1826-1830.

21. Gill, C. C., Buchannon, K. W., and Westdal, P. H. 1969. Susceptibility to the yellow dwarf virus of barley varieties grown in Manitoba, and assessment of African varieties for tolerance. Can. J. Plant Sci. 49:287-292.

22. Goblirsch, C. A., Horsley, R. D., and Schwarz, P. B. 1996. A strategy to breed lowprotein barley with acceptable kernel color and diastatic power. Crop Sci. 36:41-44.

23. Grafton, K. F., Poehlman, J. M., Sechler, D. T., and Sehgal, O. P. 1982. Effect of barley yellow dwarf virus infection on winter survival and other agronomic traits in barley. Crop Sci. 22:596-600.

24. Halbert, S., and Voegtlin, D. 1995. Biology and taxonomy of vectors of barley yellow dwarf viruses. Pages 217-258 in: Barley Yellow Dwarf: 40 Years of Progress. C. J. D'Arcy and P. A. Burnett, eds. American Phytopathological Society Press, St. Paul, MN.

25. Hewings, A. D., and Eastman, C. E. 1995. Epidemiology of barley yellow dwarf in North America. Pages 75-106 in: Barley Yellow Dwarf: 40 Years of Progress. C. J. D'Arcy and P. A. Burnett, eds. American Phytopathological Society Press, St. Paul, MN.

26. Hoffmann, T. K., and Kolb, F. L. 1998. Effects of barley yellow dwarf virus on yield and yield components of drilled winter wheat. Plant Dis. 82:620-624.

27. Jensen, S. G., and D'Arcy, C. J. 1995. Effects of barley yellow dwarf virus on host plants, Pages 55-74 in: Barley Yellow Dwarf: 40 Years of Progress. C. J. D'Arcy and P. A. Burnett, eds. American Phytopathological Society Press St. Paul, MN.

28. Karababa, E., Schwarz, P. B., and Horsley, R. D. 1993. Effect of kiln schedule on micromalt quality parameters. J. Am. Soc. Brew. Chem. 51:163-167.

29. Kunze, W. 1996. Malt production. Pages 88167 in: Technology, Brewing and Malting. Versuchs und Lehranstalt für Brauerei, Berlin.

30. Lister, R. M., and Rochow, W. F. 1979. Detection of barley yellow dwarf virus by enzyme-linked immunosorbent assay (ELISA) Phytopathology 69:649-674.

31. Martin, R. R., and D'Arcy, C. J. 1995. Taxonomy of barley yellow dwarf viruses, Pages 203-214 in: Barley Yellow Dwarf: 40 Years of Progress. C. J. D'Arcy and P. A. Burnett, eds. American Phytopathological Society Press, St. Paul, MN.

32. Orlob, G. B., and Arny, D. C. 1961. Some changes accompanying infection by barley yellow dwarf virus. Phytopathology 51:768775.

33. Pike, K. S. 1990. A review of barley yellow dwarf virus grain yield losses. Pages 356-361 in: World Perspectives on Barley Yellow Dwarf. P. A. Burnett, ed. CIMMYT Mexico, D.F., Mexico.

34. Schwarz, P. B., D'Appolonia, B. L., Jansky, J. J., Harrold, R. L., Cummings, E. L., and Scheetz, M. 1989. The quality of the regional (North Dakota, Minnesota, and South Dakota) 1989 barley crop. Bull. N. D. Barley Counc. 
35. Schwarz, P. B., and Horsley, R. D. 1996. A comparison of North American two-row and six-row malting barley. Brew. Tech. 4:48-55

36. Schwarz, P. B., Jansky, J. J., Harrold, R. L., D'Appolonia, B. L., Cummings, E. L., and Kapphahn, M. E. 1990. The quality of the regional (North Dakota, Minnesota, and South Dakota) 1990 barley crop. Bull. N. D. Barley Counc.
37. van Regenmortel, M. H. V., Fauquet, C. M., Bishop, D. H. L., Carstens, E. B., Estes, M. K., Lemon, S. M., Maniloff, J., Mayo, M. A., McGeoch, D. J., Pringle, C. R., and Wickner, R. B. 2000. Virus Taxonomy: Seventh Report of the International Committee on Taxonomy of Viruses. Academic Press, San Diego, CA.

38. Williams, P. C. 1973. The use of titanium dioxide as a catalyst for large-scale Kjeldahl determination of the total nitrogen content of cereal grains. J. Sci. Food. Agric. 24:343-348.

39. Yount, D. J., Martin, J. M., Carroll, T. W., and Zaske, S. K. 1985. Effects of barley yellow dwarf virus on growth and yield of small grains in Montana. Plant Dis. 69:487-491.

40. Zadoks, J. C., Chang. T. T., and Konzak, C. F. 1974. A decimal code for the growth stages of cereals. Weed Res. 14:415-421. 